\title{
Transparência no Sistema Único de Saúde: inciativas e desafios na divulgação eletrônica das listas de espera
}

Transparency in the Sistema Único de Saúde: initiatives and challenges in the electronic dissemination of waiting lists

Transparencia en el Sistema Único de Saúde: inciativas y desafíos en la divulgación electrónica de las listas de espera

Letícia de Oliveira Fraga de Aguiar ${ }^{1}$ Antonio Carlos Onofre Lira ${ }^{2}$

RESUMO. Objetivo: Este trabalho analisou o processo de implantação da transparência e divulgação das listas de espera por procedimentos assistenciais eletivos na saúde pública do Brasil, entendendo a transparência como estratégia potencial de promover maior equidade no acesso aos serviços de saúde. Metodologia: Foi realizada uma cuidadosa revisão de literatura e levantamento documental normativo. Resultados: Identificou-se iniciativas e mudanças provocadas pela obrigatoriedade da publicização destas listas no Brasil e em experiências internacionais. Conclusão: É notória a importância da transparência na saúde, por meio da divulgação eletrônica das filas de espera para procedimentos eletivos no Sistema Único de Saúde (SUS), como estratégia de promover a equidade no acesso e possibilitar a ampla fiscalização e acompanhamento pelos pacientes, além do controle exercido por todos os órgãos de controle da Administração Pública e da sociedade.

Palavras-chave: Regulação e fiscalização em saúde. Acesso aos serviços de saúde. Governança clínica. Equidade no acesso aos serviços de saúde. Listas de espera.

ABSTRACT. Objective: This work analyzed the process of implementation of transparency and dissemination of waiting lists for elective health care procedures in Brazil, understanding transparency as a potential strategy to promote greater equity in acess to health services. Methodology: It was verified on a careful review of the literature and a normative survey. Results: Initiatives and changes was identified as mandatory publication of these lists in Brazil and international experiences. Conclusion: The importance of transparency in health is evident throught the electronic dissemination of queues for elective procedures in the Sistema Único de Saúde (SUS), as a strategy to promote equity in acess and make possible the extensive supervision and monitoring by patients, in addition to the control exercised by the public administration and society.

Keywords: Health Care Coordination and Monitoring. Health services accessibility. Clinical governance. Equity in acess to health services. Waiting lists.

RESUMEN. Objetivo: El estudio hizo un análisis del proceso que estableció la divulgación transparente de las listas de espera por los procedimientos médicos electivos de salud

\footnotetext{
1 Especialista em Direito Sanitário e Mestranda em Saúde Coletiva. E-mail: leti.df@gmail.com

2 Doutor em Informática Médica e Pós-doutor em Planejamento e Economia da Saúde. E-mail: antonio.lira@segurosunimed.com.br
} 
pública en Brasil, creyendo que la transparencia tiene el potencial de promover oportunidades iguales para obtenerse los tratamientos en establecimientos de salud. Metodología: Fue hecho una revisión exhaustiva de la literatura y la norma, Resultados: Se identificaron iniciativas y cambios provocados por la obligación de publicarse las listas de espera en Brasil, así como ocurre en otros países. Conclusión: Es muy importante la divulgación de las listas de espera por los procedimientos médicos electivos del Sistema Único de Salud de Brasil (SUS) como estrategia para lograr equidad en la obtención de los tratamientos, así como para que los pacientes, la sociedad y la administración pública hagan el control y la fiscalización del acceso.

Palabras Ilave: Regulación y Fiscalización en Salud. Accesibilidad a los servicios de salud. Gestión clínica. Equidad en el acceso a los servicios de salud. Listas de espera.

\section{Introdução}

A Constituição Federal Brasileira de 1988 (1) prevê o acesso à informação como um direito fundamental do cidadão, que deve ser assegurado e que foi regulamentado pela Lei 12.527/2011(2). Para Zorzal e Rodrigues (3), a disponibilização transparente da informação é um dos mecanismos que garantem a promoção desses direitos, fortalecem a democracia, ampliam o exercício da cidadania, ajudam a promover o controle social, inibem a corrupção, entre outros.

A transparência na gestão pública é considerada princípio fundamental e uma forma de democratização do acesso às informações públicas, portanto qualquer iniciativa que estabeleça formas de transparência e publicização de informações acerca da gestão, resguardadas as ressalvas legais, são consideradas boas práticas de governança.

Na saúde pública, para além da prestação de contas previstas legalmente, há pouca prática recorrente de transparência nas ações, ofertas e listas de espera por atendimento pelos usuários do Sistema Único de Saúde (SUS).

O Ministério da Saúde em cumprimento às suas atribuições legais de acompanhar, controlar e avaliar as ações e os serviços de saúde tem desenvolvido ações como o Programa Nacional de Avaliação dos Serviços de Saúde (PNASS) que avalia a totalidade dos estabelecimentos de atenção especializada em saúde, ambulatoriais e hospitalares, e de controle como a Central Nacional de Regulação de Alta Complexidade (CNRAC) que organiza a referência interestadual de pacientes que necessitam de assistência em alta complexidade. No entanto, não há nenhuma iniciativa ou discussão acerca de proposta para normatização sobre transparência de filas, como forma de controle e acompanhamento no SUS. 
A oferta insuficiente de serviços no SUS é um dos grandes entraves para garantir o acesso à população usuária, não conseguindo assim cumprir os princípios legais de universalidade e integralidade da atenção. Diante disso, a organização da demanda de usuários por serviços se dá por meio de estruturação de filas de espera.

A revista Radis (4), em reportagem, aponta que a fila ainda é a maneira mais eficaz e democrática de organizar uma demanda - desde que siga um ordenamento, obedeça a critérios e, no caso da saúde, leve em conta a situação de risco dos usuários. Do contrário, o fim da fila pode ser apenas o começo do problema.

$\mathrm{Na}$ saúde, estas filas são virtuais e se caracterizam como listas de espera para agendamento de procedimentos, em acordo com a necessidade e requisição do profissional assistente para cada paciente, classificadas por algum critério ou protocolo assistencial.

Considerando que a transparência contribui para a redução do clientelismo no SUS, este trabalho realizou levantamento de iniciativas nacionais e internacionais, por meio da divulgação eletrônica, na internet, das listas de espera por procedimentos eletivos, como potencial estratégia para promover a equidade no acesso aos serviços públicos de saúde e viabilizar a efetiva transparência no acesso à informação.

\section{Metodologia}

O tipo da pesquisa adotado neste trabalho foi uma revisão bibliográfica analítica com duas abordagens: o levantamento de experiências internacionais e as iniciativas no Brasil sobre a transparência das filas de espera na saúde pública, e a outra, um levantamento normativo existente acerca do tema, buscando apresentar o estado da arte e o que tem produzido sobre o tema investigado, buscando uma integração de opiniões, conceitos e ideias. Foi conceituada a transparência e sua importância na gestão pública, especialmente na área da saúde, ressaltando ações de governança para práticas de boa gestão.

Foram selecionados trabalhos acadêmicos e artigos publicados sobre o tema nos buscadores Pubmed (www.pubmed.gov) e BVS (www.bvsalud.org), sem uma restrição temporal e, realizadas buscas em sítios institucionais dos poderes executivo e legislativo municipais, estaduais e federal. As seguintes palavras-chave foram consideradas: Health 
Care Coordination and Monitoring, Health services acessibility, clinical governance, equity in acess, waiting list. Por meio deste material levantou-se experiências e legislações nacionais e internacionais sobre o tema, para identificar atitudes de governança e transparência que caracterizem boas práticas de gestão na área da saúde pública, no Brasil e em outros países.

\section{Resultados e discussão}

Diversas são as publicações científicas acerca da transparência na administração pública, dada à vasta legislação vigente no Brasil. Do levantamento bibliográfico realizado foram selecionados 22 artigos científicos relacionados ao tema de pesquisa e selecionados 08 para os descritores escolhidos. Do levantamento normativo e documentos oficiais foram selecionadas leis, decretos e portarias específicas para o tema abordado.

Comumente, e com maior amparo legal, a transparência na administração pública se aplica às questões de accountabillity, publicizando dados relativos à execução orçamentária e financeira das instituições, aos gastos com as aquisições de materiais e serviços (licitações), à remuneração de servidores e relatórios de gestão.

Silva (5) alerta que na Administração Pública brasileira, a transparência, que é decorrência do Estado Democrático de Direito, este concebido pela Constituição Federal de 1988, visa objetivar e legitimar as ações praticadas pela Administração Pública por meio da redução do distanciamento que a separa dos administrados.

De acordo com o Instituto Brasileiro de Governança Corporativa (IBGC), 2009 (6), transparência significa a disponibilização para as partes interessadas das informações que sejam de seu interesse e não apenas aquelas impostas por disposições legais. 
Quadro 1. Transparência no setor público

\begin{tabular}{|c|c|c|}
\hline Origem/ano & $\begin{array}{l}\text { revista.tce.mg.gov.br/Conte } \\
\text { nt/Upload/Materia/1682.pdf } \\
\text { /2012 }\end{array}$ & $\begin{array}{l}\text { http:www.uel.br/revistas/in } \\
\text { formacao/ } 2015\end{array}$ \\
\hline Autores & $\begin{array}{l}\text { Heloisa } \\
\text { Helena } \\
\text { Nascimento } \\
\text { Rocha }\end{array}$ & $\begin{array}{l}\text { Zorzal L; } \\
\text { Rodrigues } \\
\text { GM. }\end{array}$ \\
\hline Título & $\begin{array}{l}\text { Transparência e } \\
\text { Accountability no Estado } \\
\text { Democrático de Direito: } \\
\text { Reflexões à luz da Lei de } \\
\text { Acesso à Informação }\end{array}$ & $\begin{array}{l}\text { Disclosure e transparência no } \\
\text { Setor público: uma análise da } \\
\text { Convergência dos princípios } \\
\text { de governança }\end{array}$ \\
\hline Objetivo & $\begin{array}{l}\text { O artigo busca discutir, com base na Lei de } \\
\text { Acesso à Informação, a relação entre } \\
\text { Accountability e transparência, bem como } \\
\text { A importância de se considerar, na } \\
\text { Interpretação do que seja informação de } \\
\text { Caráter público, o Direito como um Sistema } \\
\text { aberto de princípios regras que Requer, do } \\
\text { aplicador, levar em conta as Circunstâncias do } \\
\text { caso concreto para decidir de forma justa. }\end{array}$ & $\begin{array}{l}\text { O artigo investiga os princípios de } \\
\text { Disclosure e transparência à luz das boas } \\
\text { Práticas de governança aplicadas ao } \\
\text { setor Público para redução da assimetria } \\
\text { da informação }\end{array}$ \\
\hline Conclusões & $\begin{array}{l}\text { O artigo aponta que é possível concluir que a } \\
\text { divulgação espontânea de informações pelo } \\
\text { Estado (Transparência ativa) e da solicitação } \\
\text { de informações, ainda que não elencadas ou } \\
\text { previstas em regulamentos (transparência } \\
\text { passiva), nasce saudável debate do que seja } \\
\text { administração pública transparente, ou para } \\
\text { utilizar expressão recentemente consagrada, } \\
\text { um governo efetivamente aberto. }\end{array}$ & $\begin{array}{l}\text { O artigo aponta que para uma verdadeira } \\
\text { democracia, torna-se imprescindível que } \\
\text { as entidades públicas disponibilizarem, } \\
\text { proativamente, informações que sejam } \\
\text { de interesse coletivo, mas, para tanto, é } \\
\text { necessário que haja transparência. Ou } \\
\text { seja, é fundamental que as informações } \\
\text { sejam 'publicizadas', compreensíveis, } \\
\text { precisas, tempestivas, confiáveis, para } \\
\text { entregar eficaz accountability, além de } \\
\text { poder contribuir para reduzir a corrupção. }\end{array}$ \\
\hline
\end{tabular}

Fonte: Elaboração própria. Base (03 e 07)

Rocha (7) lembra que uma administração pública transparente significa um governo efetivamente aberto, ou seja, pautado pela transparência ativa onde a divulgação espontânea das informações, e pela transparência passiva onde as informações são solicitadas.

Para Zorzal e Rodrigues (3),

a informação sob a tutela do Estado é um bem público e sua evidenciação deve ser por iniciativa da administração pública, de forma espontânea, proativa, independente de qualquer solicitação, ou seja, transparência ativa, como definido em lei. Cabe, portanto, a essas instituições identificar aquilo que é mais demandado pela sociedade e anteciparem-se para disponibilizar isso, proativamente, na Internet e/ou outros meios, a fim de facilitar que os stakeholders (partes interessadas) a conheçam. 
$\mathrm{Na}$ área da saúde pública, sob o ponto de vista de cumprimento dos preceitos legais e econômicos, são cumpridas as exigências legais para a prestação de contas financeiras, no entanto, do ponto de vista assistencial, não é rotina da gestão a divulgação e transparência à população de informações acerca do acesso aos serviços de saúde.

É notório o impasse quanto à transparência das listas de espera para consultas, procedimentos e exames no SUS. Um dos problemas bastante recorrentes é o tempo em que usuários esperam para obter atendimento, seja para consultas, exames ou procedimentos de média ou alta complexidade ambulatorial ou hospitalar. Essa longa espera termina por gerar uma grande demanda reprimida, numa fila virtual de espera.

Para Sarmento (8),

\begin{abstract}
a fila de espera é uma lista de pacientes que necessitam de um mesmo tratamento ou serviço médico, cuja demanda é maior que a oferta. Metaforicamente, os pacientes na fila habitam uma sala de espera virtual, aguardando um mesmo procedimento, sendo chamados um por vez, de acordo com a ordem da fila. A fila de espera para cirurgias eletivas é uma realidade em muitos hospitais gerais do país, com nuances regionais quanto aos procedimentos com fila maior ou menor, seja medida em número de pacientes ou em tempo de espera.
\end{abstract}

Ainda Sarmento (8) ressalta que ao invés de causar revolta, a transmissão destas informações, em geral, conforta e diminui a ansiedade do paciente na fila, que sabe ter seu problema acompanhado de forma séria e organizada.

Quando se fala em dar transparência no acesso da assistência à saúde, as iniciativas são isoladas e pontuais, sem um alicerce jurídico nacional que obrigue o gestor da saúde a divulgar as filas de espera de pacientes para procedimentos eletivos a serem realizados no serviço público.

Para Marinho (9),

o primeiro passo para enfrentamento do problema das filas é dimensionar o real tamanho dela e dar visibilidade a estas. A divulgação da fila irá impedir ou minimizar situações como: venda de consultas ou de lugar na fila; privilégio por influência política; favorecimento por conhecer os funcionários ou os profissionais de saúde; criação de uma fila paralela; mascarar o real problema e tamanho da fila e impedir adulteração da fila real.

Há, no entanto, exemplos de municípios e estados brasileiros, seja por decisão gestora ou por acordos com o Ministério Público ou o Poder Judiciário, que aprovaram leis que obrigam a publicização das listas de espera no SUS. 
Quadro 2: Legislação brasileira relativa à transparência das listas de espera no SUS.

\begin{tabular}{|c|c|c|c|}
\hline Origem & Título/número/Ano & Objetivo & Status \\
\hline Brasil- Senado Federal & $\begin{array}{l}\text { Projeto de Lei do } \\
\text { Senado } n^{\circ} 393 \text {, de } \\
2015\end{array}$ & $\begin{array}{l}\text { Dispõe sobre a obrigatoriedade } \\
\text { de publicação na internet, com } \\
\text { atualização semanal, da lista de } \\
\text { espera dos pacientes que serão } \\
\text { submetidos a cirurgias médicas } \\
\text { eletivas realizadas com recursos } \\
\text { do Sistema Único de Saúde } \\
\text { (SUS) e dá outras providências. }\end{array}$ & $\begin{array}{c}\text { Em } \\
\text { tramitação }\end{array}$ \\
\hline $\begin{array}{l}\text { Estado de Santa } \\
\text { Catarina }\end{array}$ & $\begin{array}{c}\text { Lei Estadual } n^{\circ} \\
17.066 . \text { DOE: } 20.452 \\
\text { de } 12 / 01 / 2017\end{array}$ & Dispõe sobre a publicação & Vigente \\
\hline Estado de Goiás & $\begin{array}{l}\text { Lei Estadual } \mathrm{n}^{\circ} 19.792, \\
\text { de } 24 \text { de Julho de } \\
2017 \text {. D.O de } \\
27 / 07 / 2017\end{array}$ & $\begin{array}{l}\text { Dispõe sobre a transparência da } \\
\text { lista de espera dos pacientes } \\
\text { que aguardam exames e } \\
\text { intervenções cirúrgicas eletivas } \\
\text { na rede estadual de saúde }\end{array}$ & Vigente \\
\hline $\begin{array}{l}\text { Município de } \\
\text { Cascavel/PR }\end{array}$ & $\begin{array}{l}\text { Lei Municipal n } 6721 \\
\text { de Junho de } 2017\end{array}$ & $\begin{array}{l}\text { Dispões sobre a publicação, no } \\
\text { portal da transparência do } \\
\text { município, as listas dos } \\
\text { pacientes que aguardam por } \\
\text { consultas, exames e vigente } \\
\text { intervenções cirúrgicas nos } \\
\text { estabelecimentos de saúde da } \\
\text { rede pública municipal. }\end{array}$ & Vigente \\
\hline Município de Arujá/SP & $\begin{array}{c}\text { Lei Municipal no } 2.803 \\
\text { de } 06 \text { de Janeiro de } \\
2016\end{array}$ & $\begin{array}{l}\text { Dispõe sobre a obrigatoriedade } \\
\text { de divulgação de listagem de } \\
\text { pacientes que aguardam por } \\
\text { consultas com especialistas, } \\
\text { exames e cirurgias vigente na } \\
\text { Rede Pública de Saúde e dá } \\
\text { outra providencias. }\end{array}$ & Vigente \\
\hline
\end{tabular}

Fonte: Elaboração própria. Base (11, 13, 14, 15 e 16)

Das iniciativas no legislativo brasileiro além da Constituição Federal de 1988 (1), a Lei №. 12.527/2011(2) e o Decreto №. 7.724/2012 (10) que tratam da garantia do direito de acesso à informação pela população brasileira, deve ser considerado o Projeto de Lei do Senado ํo. 393, de 2015 (11) em tramitação, que dispõe sobre a obrigatoriedade de publicação na internet, com atualização semanal, da lista de espera dos pacientes que serão submetidos a cirurgias médicas eletivas realizadas com recursos do Sistema Único de Saúde.

É importante destacar que o município de Itajaí/SC com a finalidade de propiciar transparência na saúde, firmou o Termo de Compromisso de Ajustamento de Conduta com o Ministério Público do Estado de Santa Catarina em novembro de 2015 (12). O município passou a publicar as listas de espera dos procedimentos de saúde a serem realizados pelo 
SUS no site da prefeitura 'www.itajai.sc.gov.br', com acesso livre a qualquer pessoa e permitindo ao paciente acompanhar sua posição na referida lista.

A Lei Estadual de Santa Catarina (13) dispõe sobre a publicação, na internet, da lista de espera dos pacientes que aguardam por consultas (discriminadas por especialidade), exames e intervenções cirúrgicas e outros procedimentos nos estabelecimentos da rede pública de saúde do Estado. Para tanto foi desenvolvido 0 portal 'listadeespera.saude.sc.gov.br' para que o cidadão tenha acesso às informações sobre a sua posição e previsão de atendimento nas listas de espera, podendo ser realizada a pesquisa pelo CPF, cartão nacional do SUS ou por central de regulação e procedimento. As informações são atualizadas semanalmente e a ordem de agendamento e atendimento dos usuários é definida a partir de critério cronológico ou avaliação da situação clínica do paciente.

Relativo a lei estadual de Goiás (14), as listas deverão constar de: data de solicitação do exame ou intervenção cirúrgica eletiva; posição que o paciente ocupa na fila de espera; informações dos inscritos habilitados; relação dos pacientes já atendidos, por meio da divulgação do número do cartão nacional de saúde (CNS); especificação do exame ou intervenção cirúrgica eletiva; estimativa de prazo para o atendimento da solicitação.

Os municípios de Cascavel/PR (15) e Arujá/SP (16) divulgam, em sítios municipais, as listas dos pacientes que aguardam por consultas, exames e intervenções cirúrgicas nos estabelecimentos de saúde da rede pública municipal.

Em toda a legislação citada no quadro 2 pode-se destacar indicadores comuns:

1. Identificação por meio do Cartão Nacional de Saúde;

2. Data de solicitação do procedimento;

3. Posição do paciente na fila;

4. Fila organizada por especialidade.

A data estimada de atendimento aparece em apenas 03 das leis pesquisadas e em todas há a prerrogativa de autorização para alteração na listagem, justificada a partir da gravidade do quadro clínico do paciente.

Ainda como experiência de divulgação de listas de espera, o Sistema Nacional de Transplantes (SNT) (17) permite a consulta das listas de espera pela busca direta do cadastro técnico de órgãos e tecidos. Para isso foi criada por meio da Portaria Ministerial no 901/2000, a Central Nacional de Transplantes (CNT) com a finalidade de aperfeiçoar o 
processo de gerenciamento e controle das listas de receptores estaduais, regionais e nacional, e de garantir a equidade e transparência na distribuição de órgãos e tecidos para transplantes e enxertos. Outro motivo foi o reconhecimento da necessidade de estabelecer mecanismos e critérios que permitissem a adequada captação de órgãos e sua consequente distribuição, sempre respeitando critérios de compatibilidade, urgência e tempo de espera, para que os órgãos e tecidos sejam destinados aos receptores ideais.

Pereira (18) aponta que a região de Ribeirão Preto através do São Paulo Interior Transplantes (SPIT) em 1986, experimentou um sistema informatizado específico, que propiciou agilidade e maior transparência aos processos, incluindo a iniciativa de disponibilizar o acesso do receptor, através da internet, à sua situação e à evolução de sua posição na lista de espera, permitindo um maior controle social e transparência do sistema.

A pesquisa acima não esgota o rol de inciativas em todo o território brasileiro. O tema transparência na saúde pública é atualmente muito discutido, principalmente por tratar-se de uma modalidade que viabiliza o controle e acompanhamento, inclusive uma forma de controle social, das ações praticadas pelo gestor, visando atender ao interesse público.

Já a experiência internacional aponta que a transparência faz parte da governança na saúde pública em diversos países da Europa e América do Norte.

Quadro 3: Experiências internacionais em transparência na saúde pública.

\begin{tabular}{|c|c|c|c|c|}
\hline Origem/ano & Autores & título & objetivo & Conclusões \\
\hline $\begin{array}{l}\text { Ciênc. } \\
\text { Saúde } \\
\text { Coletiva. } \\
2011\end{array}$ & $\begin{array}{l}\text { Conill EM, } \\
\text { Giovanella L, } \\
\text { Almeida PF. }\end{array}$ & $\begin{array}{l}\text { Listas de } \\
\text { espera em } \\
\text { sistemas } \\
\text { públicos: da } \\
\text { expansão da } \\
\text { oferta } \\
\text { para um } \\
\text { acesso } \\
\text { oportuno? } \\
\text { Considerações } \\
\text { a partir do } \\
\text { Sistema } \\
\text { Nacional de } \\
\text { Saúde } \\
\text { espanhol. }\end{array}$ & $\begin{array}{l}\text { O artigo discute a } \\
\text { problemática } \\
\text { Dos tempos de espera apartir } \\
\text { do } \\
\text { Estudo do Sistema Nacional } \\
\text { de } \\
\text { Salud (SNS) espanhol. } \\
\text { Apontaas } \\
\text { Peculiaridades do processo de } \\
\text { centralização espanhol e } \\
\text { Interesses de ordem } \\
\text { econômica, } \\
\text { Política e corporativa foram } \\
\text { Mencionados como fatores } \\
\text { que } \\
\text { Interferem na regulação, na } \\
\text { Transparência e no } \\
\text { gerenciamento das listas. }\end{array}$ & $\begin{array}{l}\text { O artigo destaca que é } \\
\text { necessário deslocara } \\
\text { Discussão do monitoramento } \\
\text { de listas e/ou } \\
\text { Da ampliação da oferta para } \\
\text { abrangera } \\
\text { Garantia de um acesso } \\
\text { oportuno. Este é o } \\
\text { Diferencial de qualidade que } \\
\text { redes } \\
\text { Orientadas pela APS devem } \\
\text { trazer para os } \\
\text { sistemas públicos de saúde. }\end{array}$ \\
\hline $\begin{array}{l}\text { Social } \\
\text { Science } \\
\text { \& amp; } \\
\text { Medicine, } \\
\text { Volume 70, } \\
\text { Issue 2, }\end{array}$ & $\begin{array}{l}\text { Oudhoff } \\
\text { JP, } \\
\text { Timmermans } \\
\text { DR, Knol DL, } \\
\text { Bijnen AB, } \\
\text { Van der Wal }\end{array}$ & $\begin{array}{l}\text { Prioritising } \\
\text { patients on } \\
\text { surgical } \\
\text { waiting lists: a } \\
\text { conjoint } \\
\text { analysis study }\end{array}$ & $\begin{array}{l}\text { O artigo apresenta pesquisa } \\
\text { feita } \\
\text { Junto a usuários e } \\
\text { profissionais } \\
\text { De saúde da Holanda, acerca } \\
\text { de }\end{array}$ & $\begin{array}{l}\text { O artigo mostra que há } \\
\text { concordância entre os } \\
\text { diversos participantes da } \\
\text { pesquisa, no } \\
\text { sentido de priorização } \\
\text { explícita dos pacientes }\end{array}$ \\
\hline
\end{tabular}




\begin{tabular}{|c|c|c|c|c|}
\hline $\begin{array}{l}\text { 2010.Pages } \\
199- \\
208\end{array}$ & G. & $\begin{array}{l}\text { on the priority } \\
\text { judgements of } \\
\text { patients, } \\
\text { surgeons, } \\
\text { occupational } \\
\text { physicians, } \\
\text { and general } \\
\text { practitioners. }\end{array}$ & $\begin{array}{l}\text { Fatores determinantes da } \\
\text { Priorização nas listas de } \\
\text { espera } \\
\text { Para cirurgias eletivas, e a } \\
\text { Consequente redução do } \\
\text { tempo } \\
\text { de espera. }\end{array}$ & $\begin{array}{l}\text { na lista de espera, a partir de } \\
\text { critérios pré- } \\
\text { estabelecidos são } \\
\text { necessários para justificar a } \\
\text { equidade e a transparência } \\
\text { na provisão de } \\
\text { cuidados. }\end{array}$ \\
\hline $\begin{array}{l}\text { Health Policy } \\
\text { Volume } 120 \\
\text { Issue } 4,377 \\
- \\
383\end{array}$ & $\begin{array}{l}\text { Rechel, Bernd } \\
\text { et al. }\end{array}$ & $\begin{array}{l}\text { Public } \\
\text { reporting on } \\
\text { quality, } \\
\text { waiting times } \\
\text { and patient } \\
\text { experience in } \\
11 \text { high- } \\
\text { income } \\
\text { countries }\end{array}$ & $\begin{array}{l}\text { O artigo apresenta } \\
\text { levantamento } \\
\text { realizado em } 11 \text { países } \\
\text { (Austrália, } \\
\text { Canadá, Inglaterra, França, } \\
\text { Alemanha, Holanda, Nova } \\
\text { Zelândia, Noruega, Suécia, } \\
\text { Suíça } \\
\text { e Estados Unidos), sobre } \\
\text { qualidade, tempo de espera e } \\
\text { satisfação do paciente na } \\
\text { saúde. }\end{array}$ & $\begin{array}{l}\text { O artigo aponta que nestes } \\
\text { países os dados } \\
\text { mais comumente } \\
\text { disponibilizados ao público } \\
\text { são os tempos de espera } \\
\text { pata tratamento } \\
\text { hospitalar. Dos } 11 \text { países } \\
\text { onde foram } \\
\text { aplicados os questionários, } \\
\text { o7 deles } \\
\text { (Austrália, Canadá, } \\
\text { Inglaterra, Holanda, } \\
\text { Noruega, Suécia e Estados } \\
\text { Unidos) publicam } \\
\text { os dados relativos a tempos } \\
\text { de espera em } \\
\text { seus principais hospitais. } \\
\text { E conclui que embora a } \\
\text { prestação de } \\
\text { informações adequadas e } \\
\text { significativas sobre } \\
\text { os prestadores de cuidados } \\
\text { de saúde seja } \\
\text { uma ferramenta essencial } \\
\text { para melhorar o } \\
\text { desempenho e aumentar a } \\
\text { transparência e a } \\
\text { responsabilização, pois nem } \\
\text { todo tipo de } \\
\text { informação é de igual mérito. } \\
\text { Muitos países } \\
\text { estão trabalhando para } \\
\text { melhorar seus } \\
\text { sistemas de relatórios de } \\
\text { qualidade com o } \\
\text { objetivo de aumentar a } \\
\text { transparência, mas } \\
\text { parece haver relutância. Os } \\
\text { motivos para isso } \\
\text { são multifacetados e } \\
\text { parecem incluir desafios } \\
\text { metodológicos persistentes } \\
\text { de ajuste de risco } \\
\text { e atribuição, problemas } \\
\text { éticos e } \\
\text { preocupações sobre } \\
\text { potenciais } \\
\text { consequências não } \\
\text { desejadas. }\end{array}$ \\
\hline
\end{tabular}

Fonte: Elaboração própria, com base (19, 20 e 21). 
Em busca de sistemas de saúde de alguns países europeus acerca do tema transparência, na Espanha, a Comunidade autônoma de Andaluzia, desde julho de 2009, publica na internet as listas de espera para cirurgias eletivas, o que possibilita 0 acompanhamento do tempo de espera pelo usuário e quando o tempo máximo definido em legislação é superado, o paciente poderá solicitar o atendimento no setor privado. (19).

Em Portugal (22), a Portaria n. 153/2017, publicada no Diário da República, 1. é série - n. 86 - 4 de maio de 2017, "define os tempos máximos de resposta garantidos (TMRG) no Serviço Nacional de Saúde (SNS) para todo o tipo de prestações de saúde sem caráter de urgência e aprova e publica a Carta de Direitos de Acesso aos Cuidados de Saúde pelos Utentes do SNS", e estabelece em caráter de informação, a obrigatoriedade dos prestadores de serviços disponibilizar em locais de fácil acesso e na internet os tempos de espera por patologias e informar ao paciente, no ato da marcação, o tempo de espera para a prestação dos cuidados, os quais ele necessita. Todo esse processo é registrado em sistema informatizado e monitorado pelo Sistema Integrado de Gestão do Acesso (SIGA SNS).

Rechel at al. (21) demonstram que países como Austrália, Canadá, Inglaterra, Holanda, Noruega, Suécia e Estados Unidos publicam relatórios contendo informações sobre os tempos de espera nos seus principais hospitais, e consideram que a prestação de informações adequadas e significativas sobre os prestadores de cuidados de saúde é uma ferramenta essencial para melhorar o desempenho e aumentar a transparência e a responsabilização.

\section{Conclusões}

Esta pesquisa evidenciou a importância da transparência na saúde, por meio da divulgação eletrônica das filas de espera para procedimentos eletivos, como estratégia de promover a equidade no acesso. Percebe-se que nos países desenvolvidos é uma estratégia adotada pelas gestões da saúde pública.

Ficou evidente a incipiência desta prática no Brasil, no entanto algumas das iniciativas legislativas federal, estaduais e municipais já demonstram um processo evolutivo nesse sentido.

É ponto comum que a divulgação eletrônica das filas traduz a transparência e promove o conhecimento do usuário acerca da organização do sistema de saúde, 
reafirmando que o acesso à informação, além de ser um direito assegurado legalmente, é efetivamente exercido na saúde.

Pode-se concluir que a manutenção de um registro público e confiável das pessoas que aguardam na fila das cirurgias eletivas, disponibilizadas na internet e atualizadas periodicamente, é um mecanismo efetivo de combate a fraudes e privilégios nestas filas, o que possibilita a ampla fiscalização e acompanhamento pelos pacientes, além do controle exercido por todos os órgãos de controle da Administração Pública e da sociedade.

\section{Referências}

1. Brasil. Constituição (1988). Constituição da República Federativa do Brasil. Brasília, DF: Senado Federal, 1988.

2. Brasil. Lei Ordinária $\mathrm{n}^{\circ} 12.527 / 2011$, de 18 de novembro de 2011 . Regula o acesso a informações previsto no inciso XXXIII do art. 5o, no inciso II do § 30 do art. 37 e no $\S$ 20 do art. 216 da Constituição Federal; altera a Lei no 8.112, de 11 de dezembro de 1990; revoga a Lei no 11.111, de 5 de maio de 2005, e dispositivos da Lei no 8.159, de 8 de janeiro de 1991; e dá outras providências.Disponível em: http://www.planalto.gov.br/ccivil 03/ ato2011-2014/2011/lei//12527.htm Acesso em 2.2.2018.

3. Zorzal L, Rodrigues GM. Disclosure e transparência no setor público: uma análise da convergência dos princípios de governança. Inf. Inf., Londrina, 2015, 20(3):113-146.

4. Revista RADIS: A medida da fila. 2015. Fundação Oswaldo Cruz, 2015. Disponível em: http://www6.ensp.fiocruz.br/radis/revista-radis/159/reportagens/medida-da-fila Acesso em 12.11.2017

5. Silva CRA. Princípio da transparência na Administração Pública. Jusbrasil. Disponível em: https://ralmeidasgc.jusbrasil.com.br/artigos/113024627/principio-datransparencia-na-administracao-publica Acesso em 2.2.2018.

6. Instituto Brasileiro de Governança Corporativa (IBGC). Código das melhores práticas de governança corporativa. São Paulo: IBGC, 2009.

7. Rocha HHN. Transparência e accountability no Estado Democrático de Direito: reflexões à luz da Lei de Acesso à Informação. Revista TCEMG - Edição Especial, 2012. Disponível em: http://revista1.tce.mg.gov.br/Content/Upload/Materia/1682.pdf Acesso 20.1.2018.

8. Sarmento Junior KMA, Tomita S, Kos AOA. O problema da fila de espera para cirurgias otorrinolaringológicas em serviços públicos. Rev. Bras. Otorrinolaringol. 2005, 71(3):256-262. 
9. Marinho A. A economia das filas no Sistema Único de Saúde (SUS) brasileiro. Repositório do Conhecimento do IPEA. Disponível em: http://repositorio.ipea.gov.br/handle/11058/1595 Acesso em 20.12.2017.

10. Brasil. Decreto № 7.724/2012. Regulamenta a Lei no 12.527, de 18 de novembro de 2011, que dispõe sobre o acesso a informações previsto no inciso XXXIII do caput do art. 5o, no inciso II do § 30 do art. 37 e no $\S 20$ do art. 216 da Constituição.Disponível em: http://www.planalto.gov.br/ccivil 03/ ato2011-2014/2012/decreto/d7724.htm Acesso em 12.12.2017.

11. Brasil. Projeto de Lei do Senado no 393, de 2015. Dispõe sobre a obrigatoriedade de publicação na internet, com atualização semanal, da lista de espera dos pacientes que serão submetidos a cirurgias médicas eletivas realizadas com recursos do Sistema Único de Saúde (SUS) e dá outras providências. Disponível em: https://www25.senado.leg.br/web/atividade/materias/-/materia/121974 Acesso em 25.10.2017.

12. Portal do Município de Itajaí/SC. Fila de Espera-Saúde. Termo de ajustamento de conduta com o Ministério Público estadual de Santa Catarina. Disponível em: https://itajai.sc.gov.br/c/fila-espera-saude Acesso em: 3.10.2017

13. Estado de Santa Catarina. Lei no 17.066, de 11 de janeiro de 2017. Dispõe sobre a publicação, na internet, da lista de espera dos pacientes que aguardam por consultas (discriminadas por especialidade), exames e intervenções cirúrgicas e outros procedimentos nos estabelecimentos da rede pública de saúde do Estado de Santa Catarina. DOE: 20.452, de 12/01/2017. Disponível em: http://leis.alesc.sc.gov.br/html/2017/17066 2017 lei.html

14. Estado de Goiás. Lei estadual ํㅜ 19.792, de 24 de julho de 2017. Dispõe sobre a transparência da lista de espera dos pacientes que aguardam exames e intervenções cirúrgicas eletivas na rede estadual de saúde. Disponível em: http://www.gabinetecivil.go.gov.br/pagina leis.php?id=21672 Acesso em: 27.07.2017.

15. Município de Cascavel/PR. Lei municipal no 6721 de junho de 2017. Dispõe sobre a publicação, no Portal da Transparência do município, as listas dos pacientes que aguardam por consultas, exames e intervenções cirúrgicas nos estabelecimentos de saúde da rede pública municipal. Publicado em. Órgão oficial eletrônico no 1814. Disponível em: https://leismunicipais.com.br/a/pr/c/cascavel/leiordinaria/2017/673/6721/lei-ordinaria-n-6721-2017-dispoe-sobre-a-publicacao-noportal-da-transparencia-do-municipio-de-cascavel-as-listas-dos-pacientes-queaguardam-por-consultas-exames-e-intervencoes-cirurgicas-nos-estabelecimentosda-rede-publica-de-saude-do-municipio-de-cascavel Acesso em: 14.06.2017

16. Município de Arujá/SP. Lei municipal no 2.803, de 06 de janeiro de 2016. Dispõe sobre a obrigatoriedade da divulgação de listagem de pacientes que aguardam por consultas com especialistas, exames e cirurgias na rede pública de saúde e dá outras providências. Disponível em: 
http://www.prefeituradearuja.sp.gov.br/Atos/Leis/Livro68 OCR/LEl\%2028032016 O $\underline{\text { CR.pdf }}$

17. Ministério da Saúde. Sistema Nacional de Transplantes. Disponível em: http://portalsaude.saude.gov.br/index.php/oministerio/principal/secretarias/sas/transpl antes/sistema-nacional-de-transplantes Acesso em 15.1.2018.

18. Pereira LA et al. Sistema Estadual de Transplantes em São Paulo: histórico, resultados e perspectivas. Disponível em: ses.sp.bvs.br/lildbitextos/docsonline/get.php?id=633 Acesso em 15.1.2018

19. Conill EM, Giovanella L, Almeida PF. Listas de espera em sistemas públicos: da expansão da oferta para um acesso oportuno? Considerações a partir do Sistema Nacional de Saúde espanhol. Ciência \& Saúde coletiva. 2011, 16(6):2783-2794. Disponível em: http://www.scielo.br/pdf/csc/v16n6/17.pdf Acesso em 15.2.2018.

20. Oudhoff JP, Timmermans DR, Knol DL, Bijnen AB, Van der Wal G. Prioritising patients on surgical waiting lists: a conjoint analysis study on the priority judgements of patients, surgeons, occupational physicians, and general practitioners. Social Science \& Medicine, 2010, 70(2):199-208.

21. Rechel $B$ et al. Public reporting on quality, waiting times and patient experience in 11 high-income countries. Health Policy, 2016, 120(4):377- 383.

22. Portugal. Ministério da Saúde. Portaria ํo153 de 04 de maio de 2017. Define os tempos máximos de resposta garantidos (TMRG) no Serviço Nacional de Saúde (SNS) para todo o tipo de prestações de saúde sem caráter de urgência e aprova e publica a Carta de Direitos de Acesso aos Cuidados de Saúde pelos Utentes do SNS. Diário da República, 1. aㅗ série, № 86, 4 de maio de 2017. Disponível em: https://dre.pt/application/conteudo/106970981 Acesso em 15.2.2018.

Recebido em: 5.5.2018

Aprovado em: 16.6.2018

\section{Como citar este artigo:}

Aguiar LOF, Lira ACO. Transparência no Sistema Único de Saúde - inciativas e desafios na divulgação eletrônica das listas de espera. Revista Cadernos Ibero-Americanos de Direito Sanitário. 2018 abr./jun, 7(2):110-123. 